\title{
Processo Migratório e Saúde Mental: Rupturas e Continuidade na Vida Cotidiana
}

\author{
LENY ALVES BOMFIM TRAD
}

\section{RESUMO}

Os movimentos migratórios constituem um tipo complexo de mobilidade social, implicando uma ruptura com os referenciais básicos que orientam a conduta individual. O presente estudo acompanha o itinerário migratório de brasileiros que emigraram para Barcelona, analisando os fatores socioculturais psicológicos que interferem no processo migratório. O conceito de processo migratório enfatiza a relação tempo e espaço. $\mathrm{Na}$ nova comunidade, os imigrantes são expostos a transformações ambientais e sociais que eles tentam gradualmente entender e incorporar, especialmente na esfera cotidiana. Neste processo podemos distinguir diferentes etapas: momentos de ruptura e de construção de uma nova realidade social.

Palavras-chave: Processo migratório; estruturação da identidade; saúde mental. 


\section{Introdução}

A necessidade de reconceituar o fenômeno da migração, tendo em vista a complexidade deste fenômeno e suas múltiplas implicações, aparece referida em estudos de demógrafos, antropólogos, psicólogos etc. Além de endossar este ponto de vista, interessa aqui destacar as repercussões da migração no marco da identidade dos sujeitos que a vivenciam, tendo como pano de fundo a trama da integração social. Os deslocamentos geográficos, sobretudo os que acarretam mudança da residência habitual, do entorno e, principalmente, dos referentes culturais básicos, produzem efeito imediato sobre a vida cotidiana, nos seus diferentes âmbitos: família, escola, trabalho e espaço público.

Embora o caráter multifacetado do fenômeno migratório tenha sido enfatizado com freqüência, sua natureza processual não foi suficientemente analisada. O termo processo pode ser descrito como o elemento temporal que indica em geral uma mudança progressiva no sistema vivo. De fato, o conceito de processo migratório encontra na dimensão temporal seu eixo fundamental.

O processo de adaptação do imigrante passa por uma complexa integração entre estruturas sociais, culturais, econômicas e políticas do velho e novo contextos, e uma profunda reorganização subjetiva, derivada das expectativas subjacentes ao movimento migratório e das dinâmicas de identificações e internalizações. Nesta perspectiva, articulam-se três elementos-chave: temporalidade, contextualização e interação entre os fatores psicológicos e socioculturais. Interessa identificar os diferentes fluxos que se cruzam no processo migratório, podendo convergir para situações mais ou menos favoráveis em relação ao bem-estar psíquico dos migrantes.

O presente artigo é resultado de uma análise de dados produzidos em estudo etnográfico realizado com imigrantes brasileiros em Barcelona, através de observação participante e entrevistas em profundidade, por cerca de dois anos. Foram analisadas as experiências de 29 imigrantes brasileiros, distribuídos em três grupos: recém-chegados ao país, residentes entre cinco e oito anos e com mais de 12 anos de permanência. No grupo estudado, analisamos seis núcleos familiares (correspondendo a cerca de 50\% do grupo investigado). Não foram incluídas situações de exílio ou migração tipicamente temporária, por motivos de estudo ou trabalho.

A principal hipótese do estudo é que a migração em si não implica malestar psíquico, mas que a saúde ou a enfermidade mental no marco do processo migratório dependem dos fluxos que se estabelecem entre as his- 
tórias pessoais prévias à imigração, as situações enfrentadas pelo imigrante no novo contexto e a estruturação da identidade. As diferentes trajetórias de imigrantes brasileiros analisadas neste trabalho reforçam esta hipótese, posto que a etiopatogenia presente no grupo investigado se estrutura nitidamente a partir de uma complexa rede de processos, na qual se complexificam elementos de diferentes categorias: sociais, mentais e materiais.

Para compreender o itinerário do imigrante e o processo de adaptação psicossocial, adotamos a concepção de momentos diferenciados da migração, proposta por Bibeau et al., e a noção de carreira moral, de Gofman (1986). Bibeau et al. (1992) distinguem dois momentos da imigração: “o tempo da ruptura", no qual se contrapõem as expectativas, as referências do imigrante sobre a realidade do país de acolhida; "o tempo da continuidade", no qual, pouco a pouco, o imigrante vai construindo seu cotidiano e se integrando ao novo país. De fato, a migração se constitui a partir de diferentes tempos: o tempo da partida, o tempo da chegada, o tempo da construção da nova realidade social no cotidiano.

A noção de carreira moral de Gofman (1986, p. 34) consiste "nas experiências de aprendizagem e conseqüentes modificações do eu" pelas quais pode passar um indivíduo e repercutem diretamente sobre a identidade e percepção de si mesmo e do mundo que o rodeia, o que implica uma "seqüência de ajustes pessoais". Como frisou Goffman, o termo pode ser utilizado para se referir a qualquer trajetória social percorrida por uma pessoa no curso de sua vida, cuja análise permite identificar mudanças ocorridas através do tempo. A partir da compreensão acerca da carreira moral do imigrante, numa perspectiva intra e intersubjetiva, é possível inferir as pautas específicas de sua conduta, seus sentimentos, como se desenvolvem as diferentes interações com os grupos circundantes, assim como o modo em que suas vivências afetam sua identidade e comportamento.

\section{Migração e Saúde Mental: risco e proteção}

Os modelos explicativos da vinculação entre migração e saúde mental predominantes até então tendem a subestimar o caráter dinâmico da relação risco-proteção, não contemplando a dimensão interativa dos diferentes aspectos presentes no fenômeno migratório e a temporalidade do processo. Além disso, migração e saúde mental são conceitos especialmente complexos, que não se prestam a uma abordagem do tipo explicativa. De fato, o processo migratório é resultado da combinação de momentos de rupturas e 
transições com outros de maior estabilidade, em que interagem fatores socioculturais e psicológicos.

Quanto à concepção de risco, é conveniente sublinhar que, embora seja possível identificar traços gerais de caráter universal, a cada época e contexto cultural correspondem condições específicas de risco e proteção. É próprio do homem atuar para identificar e defender-se dos riscos sociais; o perigo é um fator intrínseco às sociedades humanas, assim como a percepção deste, o que permite aos indivíduos enfrentarem os riscos com certo nível de equilíbrio (Romani, 1995).

Além de identificar os fatores e circunstâncias que convertem a experiência migratória em psicologicamente conflitante, é igualmente necessário identificar os elementos que atuam como fatores de proteção e favorecem uma adaptação psicossocial satisfatória. Constituem fatores de proteção aqueles que operam como facilitadores no enfrentamento de riscos sociais. Em outras palavras, que produzem efeito inverso aos fatores de risco.

No caso da migração, Bibeau et al. (1992) identificam os fatores de risco e proteção com o bem-estar psíquico e social a partir de pares diádicos, dialeticamente relacionados: perdas / ganhos; isolamento / integração social; segurança / insegurança; segmentação / integridade; ruptura / continuidade; baixa auto-estima / auto-estima elevada. Esses elementos interagem dinamicamente no desenvolvimento do processo migratório.

Para compreender a dinâmica da relação risco/proteção no processo migratório, é necessário valorizar as experiências pessoais de indivíduos e grupos provenientes de diferentes contextos socioculturais, como compreender as características dos próprios contextos. Como assinalam Bibeau et al. (1992), podemos distinguir três níveis de contexto social, sobre os quais o fenômeno migratório produz impactos: o contexto imediato (o domicílio, a família, o trabalho); o microcontexto (valores sociais, matrizes lingüísticas) e o macrocontexto (economia, sistema coletivo de normas e valores, políticas culturais, estrutura familiar).

Os mesmos autores denominam experiências pivot situações típicas geradas no âmbito individual ou coletivo na vida dos imigrantes, englobando os três contextos referidos, e que são suscetíveis de fragilizar a pessoa e gerar problemas para a saúde mental. As experiências pivot, que eventualmente se traduzirão em sintomas individuais ou sociais de mal-estar, dependem especialmente da vida cotidiana dos imigrantes no país de acolhida, do nível e da qualidade da integração social e da elaboração psíquica da migração. Em última instância, trata-se de um cálculo compensatório: até que 
ponto a vida naquele país compensa as perdas subjacentes à migração?

Durante a investigação, foi possível detectar algumas situações que conformavam perspectivas de mais proteção ou fragilidade para o imigrante. A realização profissional, o sentir-se acolhido pela comunidade local, a elaboração relativamente satisfatória do luto migratório são alguns dos elementos que contribuíram para o bem-estar psíquico dos sujeitos. Para o imigrante, é importante o suporte material, assim como a satisfação no âmbito das relações sociais e afetivas. Em contrapartida, o sentir-se marginalizado na comunidade, o não-reconhecimento da sua capacidade profissional ou o sentimento generalizado de inadequação repercutem negativamente na sua saúde mental.

\section{A Ruptura do Cotidiano}

Antes de focalizar a trajetória do imigrante brasileiro a partir do momento em que chega a Barcelona, convém situar as motivações do grupo para a escolha desse destino, assim como as expectativas adjacentes a tal escolha. As teses vigentes sobre migração apontam os fatores econômicos, seguidos das motivações políticas, como os principais impulsores dos movimentos migratórios. Entretanto, não foram fatores econômicos os mais referidos pelos entrevistados quando indagados sobre a motivação para sair do Brasil.

No coletivo investigado, constata-se que a decisão de emigrar, ainda que impulsionada por razões diversas, era um projeto pessoal há muito acalentado: "viver em um país de Primeiro Mundo". A escolha da Espanha como país de destino se justificou sobretudo por motivos de ordem prática. O mais referido foi a semelhança de costumes e idioma, tendo sido destacado em muitos depoimentos que o fato de considerar mais fácil aprender o espanhol do que outros idiomas, como francês ou inglês, foi fundamental. Outro fator referido, determinante para aqueles que eram descendentes de espanhóis, foi a crença de que na Espanha seria mais fácil entrar e depois legalizar a situação de residência e trabalho.

Referindo-se especificamente à opção por Barcelona, os informantes destacaram seu caráter cosmopolita ou características do seu entorno (mar, clima, arquitetura) como decisivos na sua escolha. Ainda ao justificarem a escolha da cidade, eram recorrentes entre os depoimentos relatos como "Barcelona é a mais européia das cidades espanholas", remetendo também aqui a noções de prestígio e ideais civilizatórios.

Interessa aqui pontuar que a maioria do grupo não havia estado antes na 
Espanha e tampouco havia realizado pesquisa mais apurada para checar se suas expectativas com relação ao país eram realistas. Mesmo aqueles que referiram ter visitado Barcelona antes, em curto período de férias, enfatizaram que a cidade lhes pareceu absolutamente estranha. Assim sendo, Barcelona se apresentava como um território a ser descortinado.

Para o imigrante recém-chegado, a primeira fase do processo de adaptação é a descoberta, a apreensão da engrenagem da vida cotidiana. Inicialmente, ele experimenta o fenômeno da euforia, no qual tudo é deslumbrante, mas depois vem o momento da aterrissagem psicológica (Tyurst, 1951 apud Tousignant, 1990). Relatos como o de Roberto eram comuns no grupo estudado:

"Eu me sentia supertenso e confuso. Tinha horas que ficava maravilhado com a cidade. Achava tudo deslumbrante (...) mas também me sentia tenso o tempo todo: eu não sabia nada daquele lugar, tudo era novo e não tinha sentido para mim (...) de repente sentia vontade de estar num bar que costumava freqüentar no Rio" (Roberto, 31 anos).

O mais provável é que na cidade em que viviam anteriormente, essas pessoas não se detivessem para observar o povo da rua, as imagens da cidade - em suma, toda uma relação de coisas que configuravam seu espaço cotidiano. Segundo Sartre:

"a consciência reflexiva do homem-no-mundo se encontra em sua existência cotidiana, frente a objetos psíquicos que são o que são, que aparecem na trama contínua de nossa temporalidade (...) que se sucedem" (Sartre, 1984, p. 188).

O mundo da vida cotidiana é uma espécie de laboratório, onde as pessoas produzem sentido e constroem explicações acerca dos fenômenos circundantes, baseando-se no que têm ao seu alcance e na interpretação dos acontecimentos vivenciados por elas e pelos que as cercam. Nos termos de Schultz (1987), o cotidiano é o âmbito da experiência humana marcada pela repetitividade, pelo automatismo. Supostamente previsível e imediatamente apreendida pelos sentidos, a vida cotidiana é sobretudo pragmática, acima de tudo utilitária e talvez realista. Essa inclinação pragmática, como enfatiza o autor, faz com que o indivíduo concentre seu interesse, em termos de conhecimento, no que é necessário à realização de suas operações e planos práticos.

O que ocorreria então se, em dado momento, o indivíduo se encontrasse 
diante de uma realidade que não lhe é familiar e que seu estoque de conhecimento não fosse suficiente para operar fluentemente? É este o caso do imigrante, quando se instala em outro país. Vale notar que a situação daquele que vem com planos de ficar não é a mesma de um turista, já que, no segundo caso, a certeza do retorno ao país de origem em breve espaço de tempo o conforta.

No caso do imigrante, como ressaltam Grimberg \& Grimberg (1994, p. 107), é muito mais difícil conciliar os sentimentos em relação ao país de origem e ao de acolhida. O incremento da confusão é maior quando se misturam culturas, idiomas, pontos de referência e recordações. O imigrante tem diante de si uma dupla referência: a de um passado cotidiano que ficou no país de origem e a nova realidade, a qual the cabe apreender. Modificamse as práticas, as formas organizativas, a rotina diária, e isto pode produzir um "choque cultural". Transforma-se um ritmo de vida: itinerários, horários, alimentação, relações de trabalho. Além disso, há que solucionar os problemas essenciais da moradia, trabalho, trâmites institucionais etc.:

"Um dia no mercado, me chamou a atenção como as meninas jovens pegavam as caixas pesadas de um lado para o outro, cortavam um peixe enorme, é diferente de Curitiba (...) e isto de pedir a tanda ${ }^{2}$ nos lugares, demorei para entender como funciona e ganhava bronca das pessoas quando não perguntava 'quien es el último' (...) mas é por isso que fico querendo entender tudo, para saber como me comportar" (Maria, 35 anos).

Os primeiros meses se caracterizam por intenso processo de reconhecimento do espaço e decodificação dos códigos de conduta ou de linguagem. Em outras palavras, consistem no processo de representação social da realidade que se apresenta. Segundo Moscovici (apud Spink, 1995), essa representação constitui atividade cognitiva que todo indivíduo desenvolve para poder se aproximar da realidade, compreendê-la e dar-lhe significado. Consiste em "um processo de aproximação da realidade, ao mesmo tempo em que a constrói". O autor distingue dois momentos nesse processo. $\mathrm{O}$ primeiro consiste em decodificar as informações e estímulos que vêm do exterior, convertendo o abstrato em algo real. O segundo consiste em converter em algo funcional e prático os novos conhecimentos adquiridos. Tudo isto será fortemente influenciado pelos sistemas socioculturais e as conjunturas políticas e econômicas dos contextos de origem e acolhida.

Para Alves \& Rabelo (1998, p. 108-119), essa relação entre representação e prática é muito mais complexa. Os autores criticam a idéia de uma 
determinação das representações sobre as práticas, de tal forma que estas sejam vistas como passíveis de serem deduzidas dos sistemas construídos de representações. Os autores propõem a revitalização do conceito de experiência, entendida como uma realidade construída por processos significativos, intersubjetivamente partilhados, e que se desdobram no seu caráter biográfico, dinâmico, indeterminado e flexível para renovadas formulações. Sobretudo, deslocam a ênfase do processo de construção de hábitos de uma ação intelectual para uma ação eminentemente prática e radicada no corpo: "na base dos processos de aquisição de hábitos não está o aprendizado intelectual de novas representações, mas o desenvolvimento de novas sínteses corporais ou modos de atentar com e para o corpo" (Alves \& Rabelo, 1998, p. 10).

Antes de tudo, a realidade da vida cotidiana apresenta-se aos indivíduos como um mundo intersubjetivo, que compartilham com outros homens. Como adverte Schultz (1987), a atitude natural que os indivíduos apresentam no âmbito da vida cotidiana e que garante a reprodução de uma ordem preestabelecida é constantemente renovada pela produção de sentidos e elaboração de significados. Do ponto de vista da saúde mental do imigrante, a vivência com a comunidade local constitui elemento-chave, de importância tanto simbólica quanto prática. A percepção de inadequação relativa ao comportamento individual e a constatação de manifestações de rejeição por parte do grupo social dominante podem produzir no sujeito estados de insegurança e desconfiança que são muito nocivos do ponto de vista psicológico. A angústia e a sensação de insegurança são imediatas.

Chama atenção a referência, constante entre os entrevistados, ao intenso processo de somatização que vivenciaram nos primeiros seis meses em Barcelona. Sintomas como crises asmáticas, gastrites e dores terríveis na coluna foram referidos pela maioria dos sujeitos ao descrever a etapa inicial de inserção na cidade catalã. Alguns problemas puderam ser observados mais de perto, entre o grupo dos recém-chegados. Foi o caso de Sonia (26 anos), que, após seis meses em Barcelona, comentava: "parece que desde que cheguei aqui tenho todas as doenças do mundo. Tive que tirar o DIU, que nunca me incomodou antes, mais aqui tive hemorragia. De repente estou tendo crises de asma (...)".

Nathan (1990) pontua que as situações que implicam choques, do ponto de vista psicológico, devem ser compreendidas a partir da relação internoexterno. No momento do choque, o problema se centra na radical transformação da estrutura que circunda o sujeito, já que o mundo externo de 
repente se modifica. Para superar esse momento e lograr a adaptação psicológica, seria necessária uma transformação: "quando na continuidade do tempo se produz uma ruptura (...) para superar um choque, de fato, é necessário transformar a ruptura em estrutura" (Nathan 1990, p. 31).

Posto de outra forma, é imprescindível superar a ausência do território abandonado e lograr adaptar-se a uma nova realidade, combinando as situações presentes com as influências de suas tradições culturais e vivências anteriores. Nesse processo, detecta-se a importância do contexto familiar. Ficou patente a diferença em termos de resiliência, sobretudo na etapa inicial, entre os que vieram sozinhos e aqueles que trouxeram a família. A presença da família revelou-se importante fator de proteção.

Inicialmente, tinha-se a expectativa de que seria mais fácil para os solteiros lidar com as dificuldades que se apresentavam no decorrer do processo migratório. Isto, de certa forma, se confirmou no processo posterior de integração com a comunidade. Entretanto, nos primeiros meses, aqueles que estavam acompanhados de cônjuge, filhos e, em menor proporção, de outros parentes, superavam com mais facilidade o choque inicial. Com base nas narrativas e observações, pudemos inferir que a possibilidade de preservar, dentro de certos limites, a rotina familiar que mantinham no Brasil, minimizava a sensação de ruptura no seu entorno cotidiano. Sobretudo quando a dinâmica familiar é harmoniosa, amplia-se a capacidade, entre seus membros, de se protegerem. Vejamos este depoimento:

"Não sei, eu acho que a gente não sentiu tanto a mudança porque alugamos imediatamente uma casa e pouco a pouco fomos colocando as coisas do nosso jeito (...) Eu, meu marido e os dois meninos tínhamos aqui dentro uma rotina muito parecida com a do Brasil. Além disso, somos muito unidos e isto ajuda a superar a saudade, as dificuldades (...) Claro que, da porta pra fora, tinha muito que aprender" (Cleonice, 46 anos).

Esse tempo de ruptura pode promover, como contraponto positivo, uma posição mais crítica diante da realidade que se apresenta. $O$ fato de não estar familiarizado com um ambiente que se impõe, se em alguns momentos provoca uma perturbação dos sentidos, em outros propicia um aguçamento da percepção. Diante da mudança de sua realidade cotidiana, o sujeito passa a refletir sobre o sentido dos fatos e fenômenos nos quais submerge a cada dia e que se apresentam como algo que não há por que questionar, nem problematizar. Quando se produz uma ruptura com a familiaridade acrítica, com o mito do natural e inquestionável, é possível desenvolver uma crítica 
da vida cotidiana (Quiroga \& Racedo, 1988, p. 13). De fato, muitos brasileiros se detinham no questionamento de hábitos, valores e características da sociedade barcelonense e demonstravam interesse em compreender suas origens. Alguns, cujo domínio do idioma era satisfatório, aproveitavam os contatos mais banais com os citadinos para construir uma espécie de história oral da cidade, o que lhes valia progressos consideráveis na adaptação ao novo entorno.

\section{A Continuidade ou o Desafio da Integração Social}

A partir do intercâmbio social, o imigrante vai conhecendo melhor os costumes da cidade e os mecanismos particulares que condicionam a rotina diária de sua gente: saber onde comprar, o que fazer, os itinerários, as perguntas-chave na interação cotidiana. À medida que se amplia o conhecimento sobre a cultura autóctone, o ciclo de relações na comunidade e o domínio do idioma (em alguns casos) conseguem inserir-se na vida da cidade com maior ou menor grau de penetração. Esse processo de aprendizagem vai mesclando os sentimentos de mudanças que experimenta o imigrante e o grau de ressentimento que isto produz nele. Também contam os interesses que nele desperte seu novo habitat, especialmente as possibilidades de crescimento pessoal e profissional.

O tipo e a intensidade de ansiedades que se manifestam no transcurso do processo adaptativo, assim como os estados de angústia ${ }^{3}$, dependem em grande parte do êxito dessa adequação. Todo o processo de integração social dos imigrantes brasileiros se constrói através de uma dinâmica complexa que integra noções tão antagônicas como solidariedade e competitividade, incluindo aqui, vis à vis, conterrâneos, outros imigrantes e autóctones. Na medida em que existe uma disputa por recursos básicos, como moradia, trabalho, assistência etc., mais eficazes se revelam os mecanismos de estigmatização entre os diferentes grupos sociais (Romani, 1995). No fragmento abaixo, a alusão à competição por recursos e seus efeitos aparece com nitidez. Neste caso, a solidariedade em relação aos problemas do outro - também imigrante - dá lugar ao ressentimento:

"Eu não entendo esta política de controle de migração deles. Uma hora dizem que já tem imigrante demais, outras dão asilo político a africano, o povo do Leste Europeu (...). Quando fizeram a anistia em 91, eu legalizei minha situação e achei que finalmente ia conseguir um bom emprego. Que nada! 
Tem estrangeiro demais nesta terra e todo dia chega mais. Não tem emprego pra todo mundo (...) De imigrante, que não seja, europeu, os únicos que se dão bem são os argentinos" (Mário, 34 anos).

No processo de inserção social do imigrante, um obstáculo que pode surgir é a diferenciação nos critérios de avaliação da qualificação ou capacidade do trabalhador no contexto de acolhida (Quiroga \& Racedo 1988, p. 77). Assim sendo, um importante desafio para os imigrantes, no contexto do trabalho, é identificar que características serão valorizadas pelos nativos nos diferentes setores profissionais. Para os brasileiros, exemplo marcante da discrepância em termos de critérios de avaliação profissional é a forma como os catalães se posicionam frente a um atributo como a criatividade, algo muito valorizado no Brasil.

"É impressionante! Eu me esforço para ser criativa no bar, fazer coisas que atraiam a clientela, mas o dono me dá bronca. Eles aqui são conservadores. A gente ouve o tempo todo no cambie nuestros costumbres. (...) Lá no Brasil, ser criativo era valorizado nos empregos. Aqui, nem pensar" (Rose, 30 anos).

Ainda no contexto do trabalho, outro aspecto conflitante é a percepção dos sujeitos de que existe um desequilíbrio entre suas habilidades profissionais ou sociais e o que lhes é permitido conquistar. De fato, os dados demonstram que, independentemente do tempo que levem na cidade, raramente conseguem exercer suas potencialidades ou assumir postos de destaque em seus respectivos ambientes de trabalho.

Ao focalizar a questão do trabalho, podemos perceber com nitidez as imbricações entre o micro e o macrocontextos nos termos propostos por Bibeau et al. (1992). No primeiro caso, locus específico de trabalho (empresa, instituição etc.), confrontam-se normas de conduta e parâmetros diferenciados de avaliação de desempenho. No segundo, que remete à conjuntura política e social do país/cidade, evidenciam-se dificuldades de conquistar um posto de trabalho num cenário de desemprego em alta. Ao comentar sobre a situação de desvantagem do imigrante, mesmo aqueles legalmente aptos a trabalhar e sindicalizados, na briga por um emprego, os brasileiros ressaltavam não poder contar com o apoio dos sindicatos. Estes, pelo contrário, se empenhavam em dificultar o acesso ao trabalho e/ou aos direitos dos estrangeiros inseridos no mercado, favorecendo e protegendo os interesses dos nativos, num contexto de crise. Um provérbio muito comum 
no Brasil, evocado por um dos entrevistados, ilustra bem o quadro descrito: "farinha pouca, meu pirão primeiro".

Com o passar do tempo, o imigrante pode recuperar progressivamente o equilíbrio psicodinâmico, ainda que nem sempre conquiste um sentimento de pertencimento ao cotidiano local. Grimberg \& Grimberg (1984) advertem que a manutenção de estados confusionais pode resultar do fracasso de uma dissociação defensiva eficaz ou da busca prematura de uma integração que ainda não se pode dar.

As situações de marginalização na comunidade local se incrementavam nos casos de brasileiros que se mantinham vinculados basicamente a subgrupos compostos de conterrâneos e outros imigrantes. É interessante marcar três aspectos que podem contribuir nesta associação: 1) nestes grupos se fortaleceu a construção de uma imagem estereotipada da população nativa, ao mesmo tempo em que persiste a tendência a estabelecer comparação de tipo maniqueísta entre "nós" e "eles"; 2) a resistência, por parte dos imigrantes, de incorporar qualquer atitude ou conduta que os aproxime mais da cultura autóctone, terminando por reforçar sua condição de estigmatizado; 3) a exclusão social a que são submetidos esses subgrupos fortalece o rancor e o negativismo entre seus membros, tornando-os ainda mais vulneráveis.

Na realidade, o que se tenta a partir dos guetos brasileiros é a reprodução do país abandonado. Ao recriar um ambiente que os aproxima do Brasil, cria-se uma pseudo-superação do luto migratório, que tem como pressuposto implícito uma recusa a efetivar o próprio movimento migratório. Vale registrar que, nas visitas às casas dos imigrantes inseridos nesse grupo, observávamos que o ambiente doméstico procurava manter-se fiel às tradições brasileiras: a comida, a música que ouviam, o cuidado com os filhos, a disposição dos objetos. Ao mesmo tempo, o movimento de afirmação da identidade brasileira situava-se dentro dos limites que não ameaçassem sua permanência no país.

É imprescindível analisar os fatores que levam muitos imigrantes a seguir por esta via. O modelo de integração que lhes é proposto pela comunidade de acolhida é absolutamente contraditório, uma vez que exige esforço de assimilação das regras sociais vigentes e, paralelamente, os exclui de uma série de direitos. Os vinte e nove casos acompanhados, em apenas cinco encontramos uma situação satisfatória de inserção profissional ou social. Durante as entrevistas, freqüentemente os relatos adquiriam um tom melancólico. Ao resgatar sua trajetória no Brasil, os imigrantes pontuavam que ali ocupavam melhores empregos e eram socialmente mais valorizados. 
Ao mesmo tempo, a exclusão emerge nesses registros como algo quase naturalizado. A grande maioria se resigna diante da situação de marginalização; simplesmente abriam mão de reivindicar o estatuto de cidadão. A expectativa daqueles brasileiros era conquistar um mínimo necessário para sobreviver ali sem muitos sobressaltos: legalizar sua residência era o objetivo mais almejado, ainda que, na prática, isto não significasse a conquista da cidadania ou a garantia de maior integração social. Essa postura reflete o baixo sentimento de auto-estima que experimentavam esses sujeitos, em estado crônico de apatia.

Vale registrar que a condição de clandestinidade incrementava os estados de ansiedade e angústia ou os sentimentos persecutórios. No grupo analisado, cinco brasileiros encontravam-se nesta situação. Em seus discursos era recorrente a alusão ao "medo de ser abordado por algum policial e enviado para o Brasil". A regularização de sua situação no país ocupava o centro de suas preocupações. Não ter os documentos em dia restringia o acesso desses brasileiros a serviços e benefícios de que a cidade dispunha. Sobretudo, impedia sua circulação para além das fronteiras espanholas, inviabilizando, por exemplo, uma visita ao Brasil.

Em cenário mais favorável, do ponto de vista psicossocial, encontravamse precisamente os brasileiros que diversificavam suas relações sociais, aproximando-se tanto dos autóctones como de outros grupos sociais. Sentiam-se mais integrados em Barcelona, o que atribuem, em grande parte, ao fato de combinarem a assimilação de novas condutas com a manifestação de seus valores de base. Nesse grupo, alguns fizeram questão de salientar que, muitas vezes, evitavam conviver com outros brasileiros que insistiam na comparação entre a realidade local e a brasileira:

"Pra dizer a verdade, eu evito ter muito contato com brasileiro. A maioria passa o tempo se queixando, criticam tudo (...) têm a mania de comparar as coisas daqui com o Brasil (...) não sei por que continuam aqui. (Roberto, 45 anos).

Nesse processo de integração, a família adquire função paradoxal. Como já havíamos pontuado antes, nos casos em que a dinâmica familiar é positiva, ela representa importante fator de proteção para seus membros. Para o imigrante, funciona como uma rede social imediata de apoio. Por outro lado, na continuidade do processo migratório, existe o risco de que seus membros se enclausurem no ambiente familiar e não se esforcem para ampliar suas relações com a comunidade. 
Neste sentido, constatamos que os solteiros penetravam mais rapidamente nas redes sociais urbanas com predomínio de autóctones, especialmente nos espaços e situações de lazer. Foi referido que a admiração dos nativos pelas manifestações culturais brasileiras, em especial a música e a dança, era elemento facilitador nesse processo. Os vínculos formados a partir das interações que se processavam nesses contextos resultaram, em alguns casos, em sólidas amizades, namoros ou casamentos.

Explorando um pouco mais a dinâmica risco-proteção no contexto do processo migratório, é interessante assinalar, a partir dos diferentes relatos, as associações que se estabelecem entre os elementos suporte material, realização profissional e satisfação, no âmbito das relações sociais e afetivas e os pares diádicos propostos por Bibeau et al. (1992). Deve-se ressalvar o fato de que não se trata de estabelecer uma relação linear e estática com referência a essas associações, posto que, no limite, pode-se afirmar que os três elementos repercutem, em certa medida, sobre os fatores de risco ou proteção mencionados pelos autores.

É evidente, por exemplo, que o suporte material, expresso em termos de condições concretas de sobrevivência (rendimentos, moradia etc.), guarda relação, para os entrevistados, com os sentimentos de segurança / insegurança, assim como de instabilidade / estabilidade. Em muitos depoimentos, foi enfatizado que a ameaça de ficar sem emprego no exterior era muito mais angustiante do que se estivessem em seu país, posto que "ali não tinham a quem recorrer".

A realização profissional, por sua vez, repercutia fortemente sobre a auto-estima dos sujeitos. Desempenhar uma função que consideravam aquém das suas potencialidades e qualificações era referido, freqüentemente, como um fator que alimentava forte sentimento de inferioridade. Vale dizer que aqui, em muitos casos, a renda percebida pelos imigrantes era considerada bastante satisfatória ${ }^{4}$, mas isto não amenizava o sentimento de frustração.

Por fim, a satisfação no âmbito das relações sociais e afetivas - que podem ser sintetizadas a partir da análise das redes sociais - foi associada de forma recorrente com as noções de isolamento / integração, assim como de segurança / insegurança. Destaca-se aqui a referência a aspectos quantitativos dessa rede (se mais ou menos reduzida) e, principalmente, qualitativos (se restrita a conterrâneos e outros imigrantes ou agregando também autóctones). Ainda com referência à qualidade, é valorizada a consistência das relações estabelecidas no que se refere a confiança, acolhida ou solidariedade. No caso da rede social mais ampla, onde predominava a interação 
com a comunidade local, as relações eram permeadas pelo sentimento de insegurança quanto à aceitação por parte do outro, remetendo assim à dialética aceitação / rejeição.

Quando focalizamos o equilíbrio entre perdas e ganhos, assim como fracasso e êxito, constata-se que, em ambos casos, os entrevistados atribuem igual importância aos três elementos antes referidos: suporte material, satisfação profissional e relações sociais.

\section{5. À Guisa de Conclusão}

No esforço de síntese da psicodinâmica do processo migratório do grupo investigado, não foi encontrada nenhuma manifestação de transtornos psicopatológicos de maior gravidade. Os quadros de apatia, em alguns casos acompanhados por crises depressivas intermitentes, constituíam indubitavelmente o problema psíquico dominante no grupo. Em um quadro mais geral, pode-se considerar que a estabilidade psíquica dependia em grande medida da dialética rejeição / aceitação e êxito / fracasso.

A incerteza quanto à aceitação por parte dos autóctones atravessa os itinerários desses imigrantes. Mesmo entre aqueles cuja inserção na comunidade local era mais satisfatória, pairava uma dúvida sobre os limites dessa integração. Para muitos, o desejo de integração não incluía abrir mão da suas raízes o que, por vezes, era percebido como uma imposição da sociedade nativa. Isto reforça as considerações de Melman (1992), quando aponta que imigrante estrangeiro se submete ao domínio de "outro clã, outro totem" e vive o dilema entre aceitar incondicionalmente esse domínio ou impor o domínio de sua filiação de origem. Assim sendo, o sentimento de pertencimento não é algo fácil de ser logrado.

Com relação à percepção acerca das noções de fracasso / êxito, é notável também sua vinculação com os projetos pessoais associados ao processo migratório. Neste sentido, as frustrações relativas às expectativas prévias à chegada no país eram mais facilmente superadas do que aquelas que se apresentam na continuidade. Ou seja, o projeto original podia ser revisto, ajustando-se às possibilidades concretas que se apresentavam.

Em contrapartida, se, no balanço de suas trajetórias, uma vez em Barcelona, os brasileiros não identificassem ganhos concretos, situações vitoriosas que justificassem "tudo pelo que passaram", o resultado costumava ser um profundo estado de desânimo. No longo prazo, esse desânimo circunstancial dava passagem ao já referido estado permanente de apatia. Nos 
casos contrários, em que predominava o sentimento de ter sido vitorioso naquele processo, as pessoas estavam bastante motivadas a encarar os desafios da integração no novo país. Para estes, a migração representou oportunidades e expansão e crescimento pessoal e profissional: "uma abertura para o mundo".

Em suma, podemos dizer que a elaboração do luto pelo país de origem e por tudo o que deixou para trás é um processo que nunca chega a se completar. Entretanto, as experiências encontradas apontam para a necessidade de manter uma coerência nessa dupla perspectiva. Talvez a saída esteja em investir no princípio de condução da vida (Heller, 1992) pautado na idéia de que viver é um processo singular, ao qual cada indivíduo pode dar uma forma final que contenha algo de seu desejo.

No processo de síntese de suas diferentes biografias vivenciado pelo imigrante, é mais fácil lograr a coerência subjetiva quando ele resgata a si mesmo no tempo histórico e sociocultural no qual está inserido. Enquanto constrói sua história em Barcelona, o imigrante vai construindo a si próprio. Para alguns, esse processo implicou crescimento do eu, a partir da consolidação de uma espécie de sentimento de identidade remodelado (Grimberg \& Grimberg, 1994); para outros, conduziu a um quebra-cabeça cujas peças ainda não conseguiram encaixar.

\section{Referências Bibliográficas}

ALVES, P. C.; RABELO, M. C. Repensando os estudos sobre representações e práticas em saúde-doença. In: ALVES, P. C.; RABELO, M. C (Org.). Antropologia da saúde: traçando identidade e explorando fronteiras. Rio de Janeiro: Relume-Dumará, 1998.

BIBEAU, G. et al. La santé mental et ses visages. Québec: Gaëtan Morin, 1992.

GOFFMAN, E. Internados: ensayo sobre la condición social de los enfermos mentales. Buenos Aires: Amorrortu, 1986.

GRIMBERG, L.; GRIMBER, R. Identidad y cambio. Barcelona: Paidos, 1994.

GRIMBERG, L.; GRIMBER, R. Psicoanálisis de la migración y del exili. Madrid: Alianza Editorial, 1984. 
HELlER, A. O cotidiano e a história. São Paulo: Paz e Terra, 1992. MELMAN,C. Imigrantes: incidências subjetivas das mudanças de língua e país. São Paulo: Escuta, 1992.

NATHAN, T. La follia degli altri. Firenze: Ponte Alle Grazie, 1990.

QUIROGA, A.; RACEDO, S. Crítica de la vida cotidiana. Buenos Aires: Cinco, 1988.

ROMANI, O. Etnografia y drogas: discusos y prácticas. In: Las adicciones, hacía un enfoque multidisciplinario. México: Instituto Mexicano de Psiquiatría, 1995, p. 1-24. v. 3

SARTRE, J. P. El ser y la nada. Barcelona: Alianza, 1984 (Colección Alianza Universitaria, v. 417).

SCHULTZ, A. Le chercheur et le quotidien. Paris: Méridiens-Klincksieck, 1987.

SPINK J. Desvendando as teorias implícitas: uma metodologia de análise das representações sociais. In: GUARESCHI P.; JOVCHELOVICH, S. (Org.). Textos em representações sociais. Petrópolis: Vozes, 1995. p.117145.

TOUSIGNANT, M. Etiologie sociale en santé mental. Québec: Université de Montreal, 1990.

\section{NOTAS}

1 Professora adjunta Instituto de Saúde Coletiva da Universidade Federal da Bahia.

2 "Pedir tanda" é uma expressão usada na Espanha que corresponde a pedir um lugar na fila de espera para algum atendimento ou serviço.

3 Freud faz uma distinção entre a "angústia real" e a "angústia neurótica": a primeira aparece em situações concretas de perigo, enquanto que a angústia neurótica é produzida por motivos internos e pode estar dissociada da realidade externa.

$4 \mathrm{Na}$ Espanha, assim como em diferentes países desenvolvidos, os trabalhos técnicos e serviços em geral podem apresentar remunerações equivalentes e por vezes superiores àquelas realizadas por profissionais de nível superior. 


\section{ABSTRACT}

The migratory process and mental health: breaks and continuity in daily life

Migratory movements constitute a complex type of social mobility, involving a break with the basic references orienting individual conduct. The current study follows the migratory itinerary of Brazilians who emigrated to Barcelona, Spain, analyzing the psychological socio-cultural factors intervening in the migratory process. The concept of migratory process emphasizes the relationship between time and space. In their new community, immigrants are exposed to environmental and social transformations, especially in daily life, which they gradually attempt to understand and incorporate. We can distinguish various stages in this process: moments characterized by breaks and the construction of a new social reality.

Keywords: Migratory process; structuring of identity; mental health.

Recebido em: 30/09/2002.

Aprovado em: 02/06/2003. 